\title{
O Maranhão pelo jornalismo efêmero dos stories: a construção de territórios em O Imparcial, Imirante e Imperatriz Online
}

\author{
Maranhão by the ephemeral journalism of stories: the construction of \\ territories on O Imparcial, Imirante and Imperatriz Online
}

Maranhão en el periodismo efímero de stories: la construcción de territorios en O Imparcial, Imirante e Imperatriz Online

Petronilio FERREIRA ${ }^{1}$

Paula Melani ROCHA ${ }^{2}$

Rafael SCHOENHERR3

\section{Resumo}

O presente artigo tem como objetivo analisar a construção de territórios nas publicações do Instagram Stories dos perfis noticiosos de O Imparcial, Imirante e Imperatriz Online. Para análise, utilizamos os conceitos de periferia e espaço de Milton Santos (2007), territórios virtuais de Barth, Fragoso, Rebs (2011) e de instantaneidade de Bradshaw (2014). Durante a semana de 14 a 18 de junho de 2021, foram catalogados e classificados os posts de acordo com o veículo, a editoria, o local da notícia e a natureza do conteúdo. Ao todo, foram mapeadas 153 publicações nos Stories do Imperatriz Online (ITZ Online), 142 nos do O Imparcial e 126 nos do Imirante. Entre os resultados observou-se que a produção tem características jornalísticas e potencialmente novas formas de transmissão de notícia após o período pandêmico.

Palavras-chave: Instagram; Stories; Jornalismo; Redes sociais; Ciberterritório.

\footnotetext{
${ }^{1}$ Jornalista pela Universidade Federal do Maranhão, mestrando no Programa de Pós-graduação em Jornalismo da Universidade Estadual de Ponta Grossa - E-mail: petronilio.fcf@gmail.com - ORCID: 0000-0002-1056-9669.

${ }^{2}$ Pós-doutora em Jornalismo pela Universidade Fernando Pessoa, professora do Programa de Pósgraduação em Jornalismo da Universidade Estadual de Ponta Grossa - E-mail:

paulamelani@gmail.com. ORCID: 0000-0001-5525-6650.

3 Doutor em Geografia pela Universidade Estadual de Ponta Grossa, professor do Programa de Pósgraduação em Jornalismo da Universidade Estadual de Ponta Grossa - E-mail:

rafaelschoenherr@gmail.com.
} 


\begin{abstract}
This article aims to analyze the construction of territories on Instagram Stories publications of the news profiles of the O Imparcial, Imirante, and Imperatriz On line. For analysis, we used the concepts of periphery and space of Milton Santos (2007), virtual territories of Barth, Fragoso, Rebs (2011) and instantaneity of Bradshaw (2014). During the week of June 14-18, 2021, posts were cataloged and classified according to the vehicle, theme, location of the news and the nature of the content.In total, 153 posts were mapped on the Stories of Imperatriz Online (ITZ Online), 142 on O Imparcial and 126 posts on Imirante. Among the results, it was observed that the production has journalistic characteristics and potentially new forms of news transmission, after the pandemic period.
\end{abstract}

Keywords: Instagram; Stories; Journalism; Social Media; Cyberterritory.

\title{
Resumen
}

Este artículo tiene como objetivo analizar la construcción de territorios en las publicaciones de Instagram Stories de los perfiles de noticias de O Imparcial, Imirante e Imperatriz On line. Para el análisis, se utilizaron los conceptos de periferia y espacio de Milton Santos (2007), territorios virtuales de Barth, Fragoso, Rebs (2011) y la instantaneidad de Bradshaw (2014). Durante la semana del 14 al 18 de junio de 2021 se catalogaron y clasificaron las publicaciones según el vehículo, la temática, la ubicación de la noticia y la naturaleza del contenido. En total, 153 publicaciones fueron mapeadas en los Stories de Imperatriz Online (ITZ Online), 142 en O Imparcial y 126 publicaciones en Imirante. Entre los resultados, se observó que la producción tiene características periodísticas y potencialmente nuevas formas de transmisión de noticias, después del período de pandemia.

Palabras-clave: Instagram; Stories; Periodismo; Redes Sociales; Ciberterritorio

\section{Introdução}

As redes sociais vêm transformando a forma de consumir e produzir notícias. Velocidade, rapidez e novas linguagens estão forçando profissionais e empresas jornalísticas a se reinventarem no jornalismo pós-industrial (ANDERSON; BELL; SRIRKY, 2013), um processo que compreende toda a produção e difusão de informações. Nesse sentido, os perfis noticiosos em sites de redes sociais têm aumentado a produção para atender a uma demanda cada vez maior de consumidores.

De acordo com o levantamento Digital News Report (2021), a pandemia tem acelerado o processo de migração das principais publicações brasileiras para o digital. O relatório aponta que a grande mídia tem perdido espaço para os sites de redes sociais, movimento que tende a crescer nos próximos anos. Dados revelam que mais de $40 \%$ dos entrevistados compartilham notícias em plataformas como WhatsApp, YouTube e Instagram. 
Buscando compreender como acontece a construção do território maranhense nesses ambientes virtuais, efêmeros e instantâneos foi realizado um levantamento quanti-qualitativo sobre as notícias publicadas no Instagram Stories dos perfis de O Imparcial, Imirante e Imperatriz Online. Para a pesquisa, os conteúdos foram tabelados e catalogados por veículo, editorias, localização da notícia e natureza da publicação (foto ou vídeo). Aliado a isso, foi descrito o conteúdo das publicações.

\section{A evolução das redes sociais e o jornalismo efêmero}

Primeiramente é necessário definir esses novos espaços para onde o jornalismo vem se estendendo. As redes sociais online são um ambiente de interação e compartilhamento entre pessoas com interesses comuns. Zenha (2018) caracteriza as redes sociais como um ambiente virtual próprio e organizado. Segundo a autora, a participação é promovida por relações de pertencimento. Recuero (2009) pontua que a grande diferença entre os sites de redes sociais e a Comunicação Mediada por Computadores é a exposição e a continuidade de interações.

Bradshaw (2014) acredita que redes sociais como o Snapchat e o Instagram estão mudando as relações sociais. Caracterizadas pela instantaneidade, permitem informações mais rápidas e banais. "Nada deve durar por muito tempo, nem deve ser perene, sólido ou imutável. A transitoriedade desta sociedade não é mais controlável, assim como a velocidade das mudanças" (ASSIS, 2020, p. 223). Assim, longas produções (tempo e espaço) tendem a ser rejeitadas e as atualizações são constantes.

Até 2011, a criação dessas publicações nas mídias sociais contava com a memória. As postagens ficavam guardadas e todos poderiam ter acesso ao que era disponibilizado pelos administradores das contas. Naquele ano, o surgimento do Snapchat revolucionou a forma de interação nas redes sociais. A diferença dele para outras plataformas é que não há a gravação de postagens. No ar por 24h, os posts desaparecem após esse intervalo de tempo.

Assis (2020) lembra que o sucesso da plataforma e a concorrência de mercado possibilitaram a criação do Instagram Stories. O serviço copiava a fórmula de sucesso do Snapchat, dentro de uma plataforma já popularizada no mundo. Esses recursos podem ser acessados na barra superior do feed. Em cada totem, é possível ver o conteúdo dos perfis que publicam conteúdo nos Stories, circulados por uma linha colorida. A ferramenta permite a publicação de textos, imagens, vídeos, emojis, caixas de perguntas, enquetes e músicas. "Há também a opção de reações rápidas ao material, 
que consistem em 8 emojis para exprimir riso, tristeza ou aplausos, por exemplo" (COSTA, 2020, p. 37). Para o Instagram, o Stories é o ambiente para "compartilhar momentos e experiências"4.

É necessário explicar que a efemeridade dos Stories não é completa. O criador do conteúdo tem a opção de salvá-lo. Esse arquivo pode ser utilizado na publicação de flashbacks (produzindo novas postagens) ou nos Highlights/Destaques. Usando a "memória” dos Stories, os Destaques são ferramentas que possibilitam chamar a atenção de novos usuários5, permanecendo disponíveis para consulta no feed. Entretanto, para a análise, eles não foram considerados devido à localização fora da aba dos Stories e à ausência de características efêmeras.

De acordo com o levantamento Digital 2021: Global Overview Report (2021), produzido pelas empresas We Are Social e Hootsuite, o Instagram é o $8^{\circ}$ site mais acessado do mundo, com 3,76 bilhões de visitas por mês. A plataforma está acima de sites como o Twitter, WhatsApp e o Yahoo. No Google, o Instagram é o $11^{\mathrm{o}}$ mais pesquisado. Atualmente, tem 1,22 bilhão de usuários no mundo, mais que o Telegram, Snapchat, Twitter e Reddit. Os dados do estudo revelam que os consumidores passam mais de dez horas por mês na plataforma. É mais tempo que em aplicativos como a Netflix, Twitter e WhatsApp Business. Ainda de acordo com o levantamento, o Brasil tem o terceiro maior número de contas no mundo. Ao todo, são 99 milhões, perdendo apenas para os EUA e a Índia.

O mercado tem fomentado a migração do jornalismo para as redes sociais. Castells (2006) lembra que essas mídias sociais são determinadas pelo consumo do usuário e as necessidades produzidas por eles. Isso permite que o jornalismo também se adeque a essa nova realidade, utilizando-as em todos os âmbitos da produção da notícia: recepção, difusão e interação. Conforme Costa (2020):

Fica evidente nessa listagem que essa utilização pode percorrer praticamente todos os âmbitos da construção de uma notícia, ou seja, é onde o trabalho do jornalista se inicia; desde a captação de pautas e, consequentemente, no relacionamento com fontes, passando pelo momento em que a notícia é publicada em formato de post, até as respostas que dá a seus públicos em forma de interação (COSTA, 2020, p. 31).

\footnotetext{
4 Disponível em: https://about.instagram.com/pt-br/features/stories. Acesso em 28 dez. 2021. Ver STORIES (s.d.).

5 Disponível em: https://business.instagram.com/blog/como-criar-e-o-que-colocar-nos-destaques-doinstagram?locale=pt_BR. Acesso em 08 dez. 2021. Ver COMO (2019).
} 
Costa (2020) lembra que a utilização dessas redes sociais por serviços de notícias está atrelada à maior necessidade de promoção dos conteúdos. Com maior alcance das publicações é possível que o portal, a revista ou o jornal atinja novos públicos consumidores. São pessoas mais jovens, entre 13 e 35 anos, segundo o levantamento Digital 2021: Global Overview Report (2021), que já não estão acostumadas ao consumo das notícias por meios tradicionais, como o jornal impresso, a TV ou o rádio. Muitas dessas publicações utilizam os recursos da plataforma para direcionar a audiência para os portais dos veículos noticiosos, gerando um fluxo contínuo.

Tais usos mantêm as características principais do jornalismo. Otto Groth (2011) caracteriza os jornais pela periodicidade, universalidade, atualidade e publicidade. A primeira é definida pelo tempo de publicação entre uma e outra edição. A segunda é a capacidade de conversar com os mais diferentes públicos, sobre os mais variados assuntos e nos mais diversos ambientes. A terceira significa que o jornal precisa estar em constante atualização, suprir a sede pelo novo e o desconhecido. Por fim, é necessário que essa produção seja vista e difundida. Tais características se mantiveram e se atualizaram nas redes sociais, dos maiores aos menores jornais.

\section{Os jornais e a construção do território}

O Imparcial6 é o jornal impresso mais antigo do Maranhão em circulação. Nunes et al. (2019) pontuam que o periódico foi fundado em 1926 como uma alternativa ao jornalismo influenciado por interesses de grandes famílias que dominavam a comunicação no Maranhão. Em 1944, o jornal foi vendido ao Grupo Diários Associados, tornando o periódico mais conservador, alinhado com os interesses do grupo. Recentemente, bateu o recorde de oito milhões de acessos ao seu portal, em maio de $2020^{7}$.

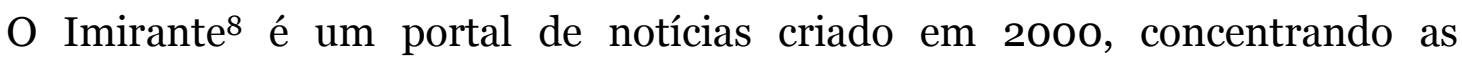
publicações do grupo Mirante, fundado em 1959. Com 33 milhões de acessos no primeiro semestre de $2 \mathrm{O}^{2} \mathrm{O}^{9}$, tem a maior audiência do estado. Ao todo, se subdivide

\footnotetext{
${ }^{6}$ O perfil no Instagram pode ser acessado no link https://www.instagram.com/oimparcial/. 7 Disponível em: https://oimparcial.com.br/noticias/2020/o6/o-imparcial-alcanca-maior-audienciada-sua-historia-86-milhoes-de-acessos/. Acesso em 28 dez. 2021. Ver O IMPARCIAL (2020).

8 O perfil no Instagram pode ser acessado no link: https://www.instagram.com/imirante/.

9 Disponível em: https://imirante.com/maranhao/noticias/2020/09/18/imirante-com-20-anos-decredibilidade-no-dia-a-dia-do-maranhense.shtml. Acesso em 28 dez. 2021. Ver IMIRANTE.COM (2020).
} 
em 5 conteúdos: Na mira, Mirante Esporte, Mirante AM, Mirante FM e o O Estado do Maranhão. Segundo a publicação de aniversário de 20 anos do portal, os serviços contam com o apoio de informações enviadas por leitores pelo WhatsApp, telefone, email e da rádio Mirante AM (IMIRANTE.COM, 2020).

Sediado em Imperatriz, região tocantina, o Imperatiz On-line ${ }^{10}$ é o único portal do interior do estado escolhido para o levantamento. Essa escolha se tornou necessária como forma de estabelecer uma melhor compreensão sobre a construção do território maranhense no ambiente virtual. De acordo com a descrição de seu perfil no Facebook, o portal foi fundado em 2013 a partir de uma página do Facebook ${ }^{11}$. Acompanhando as atualizações da internet, está presente no YouTube, Instagram e Facebook. Autodenominado independente, afirma trazer notícias de Imperatriz e região.

No Instagram, os portais têm amplo número de seguidores. O maior é o Imirante, com mais de 467 mil. Logo após, vem o Imperatriz Online, com 201 mil. Por fim, O Imparcial Online tem 195 mil. As publicações de cada jornal guardam diferenças entre si. Entretanto, todas se igualam na reduzida utilização de recursos nativos disponíveis na ferramenta e no conteúdo de notícias sobre o Maranhão.

Dois desses portais - O Imparcial e o Imirante - estão sediados em São Luís. Cidade mais populosa do estado, com 1.1 milhão de habitantes ${ }^{12}$, é o principal porto do meio norte do país. Única capital fundada por franceses, invadida por holandeses e colonizada por portugueses, São Luís guarda um patrimônio histórico, cultural e arquitetônico incalculável nos mais de 409 anos de história. Como importante centro financeiro e político do Maranhão, concentra a maior parte da produção e geração de notícias do estado.

Distante $634 \mathrm{~km}$ de São Luís, a segunda maior cidade do Maranhão está localizada às margens do rio Tocantins. Imperatriz concentra uma população de 300 mil habitantes ${ }^{13}$. A localização privilegiada permite que seja o principal entroncamento do estado. Fundada em 1852, teve o desenvolvimento favorecido com a construção da BR-010 e da Ferrovia Carajás.

\footnotetext{
${ }^{10} \mathrm{O}$ perfil no Instagram pode ser acessado no link https://www.instagram.com/imperatrizonline/. ${ }^{11}$ Disponível em: https://www.facebook.com/ImperatrizOnline/about/?ref=page_internal. Acesso em 28 dez. 2021. Ver IMPERATRIZ (2013).

${ }^{12}$ Disponível em: https://cidades.ibge.gov.br/brasil/ma/sao-luis/panorama. Acesso em 18 jul. 2021. Ver IBGE (2017).

13 Disponível em: https://cidades.ibge.gov.br/brasil/ma/imperatriz/panorama. Acesso em 30 dez. 2021. Ver IBGE (2017a).
} 
Cabe ressaltar o tamanho do estado do Maranhão. A unidade da federação tem o oitavo maior território do país. A grande extensão e a posição privilegiada (entre a Amazônia, o Cerrado e a Caatinga) favorecem a riqueza cultural, econômica e social. Ao todo, são mais de sete milhões de pessoas vivendo nos 217 municípios ${ }^{14}$. Por questões históricas, o centro de poder econômico e político está localizado no meio norte, na Ilha de Upaon-Açú. A ilha, que tem apenas uma saída terrestre para o continente, abriga a capital e outros quatro municípios, reunindo 1,5 milhões de habitantes ${ }^{15}$. Nesse ambiente, cobrir um território tão vasto como o Maranhão é uma tarefa árdua para os jornais localizados na capital.

Santos (2007) pontua que a noção sobre o pertencimento depende do local em que a pessoa está inserida. "Enquanto um lugar vem a ser condição de pobreza, um outro lugar poderia, no mesmo momento histórico, facilitar o acesso àqueles bens e serviços que lhe são teoricamente devidos, mas que de fato, lhe faltam" (SANTOS, 2007, p. 107).

Straubhaar (2019) explica que as relações de pertencimento com o local são feitas de duas formas. A primeira, de baixo para cima, e a segunda, de cima para baixo. Nesse sentido, por mais que haja um movimento de identificação nacional, formado por aristocratas políticos, a periferia também produzirá a sua forma de manifestação. O interior do Maranhão é um ambiente plural e diverso. Contudo, essa diversidade não é mostrada pelos grandes meios de informação da capital, como será demonstrado adiante. Santos (2007) nota que

Indivíduos que disponham de uma soma de capital, formação cultural e capacidade física equivalente, ocupados num mesmo tipo de atividade - para não falar senão dessas qualidades comuns - são, sem embargo, dotados de possibilidades efetivas sensivelmente desiguais, conforme os diferentes pontos de espaços em que se localizem (SANTOS, 2007, p. 108)

Para Santos (2007), a acessibilidade é uma forma importante para entender esses locais periféricos. Ele ressalta que ela não acontece de forma igualitária em todo o espaço, mas que também o espaço determina o acesso que o indivíduo pode ter aos direitos. Quando analisamos esse acesso à internet no Maranhão, é possível perceber

\footnotetext{
14 Disponível em: https://cidades.ibge.gov.br/brasil/ma/panorama. Acesso em 29 dez. De 2021. Ver IBGE (2017b).

15 Disponível em: https://imirante.com/oestadoma/noticias/2015/o9/10/ilha-ja-tem-mais-de-1-5milhao-de-habitantes/. Acesso em: 28 dez. 2021. Ver REGIÃO (2021).
} 
a disparidade. De acordo com dados do IBGE, o estado tem o segundo menor número de domicílios com acesso à rede mundial de computadores. Segundo o levantamento, o celular é o mais utilizado durante o acesso. Entretanto, apenas 70\% dos domicílios têm um pacote de dados móveis, internet ou telefonia (CRESCE, 2021).

Straubhaar (2019) explica que essa falta de acessibilidade e relação com os múltiplos espaços da internet não é fomentada exclusivamente pela disponibilidade. $\mathrm{O}$ autor ressalta que, em muitos casos, pessoas de menor escolaridade tendem a acessar menos as redes sociais. De acordo com o IBGE, em 2019, o Maranhão era o estado brasileiro com maior percentual de pessoas sem instrução, apresentando a quarta maior taxa de analfabetismo do país ${ }^{16}$.

A dificuldade no acesso a recursos financeiros pelas empresas jornalísticas e a baixa escolaridade da população podem ajudar a explicar a falta de iniciativas de sucesso no Stories de portais de notícias no interior do estado. Essa realidade é agravada ao analisarmos o uso das redes sociais. Poucos jornais têm recursos para manter as coberturas jornalísticas e, principalmente, para dar conta de um amplo espaço de mais de 329 mil km², com uma população diversa de 7 milhões de pessoas ${ }^{17}$.

Essa realidade pode ajudar a formar um ciclo sem fim de escassez de informação. Santos (2007) explica que o homem produtor é dependente da acessibilidade de recursos e formatos. Já o homem consumidor também é dependente da acessibilidade. "O grau desta última faz com que o homem continue mais ou menos dependente das condições do mercado local" (SANTOS, 2007, p. 114). Com isso, longe dos centros econômicos e de produção da informação, o maranhense do continente é obrigado a consumir notícias da ilha, distribuídas para todo o estado.

Para Barth, Fragoso e Rebs (2011), a internet tem ajudado a diversificar o território. Isso acontece porque múltiplas sociedades se encontram em um ambiente vasto e dinâmico. Aliado a isso, as redes sociais permitem interação com aquilo o que é postado. Seja reagindo com emojis ou comentando em publicações, as pessoas estão promovendo dados de uma interação complexa, construindo um ambiente de

\footnotetext{
${ }^{16}$ Para o IBGE existem quatro Níveis de Instrução: Sem instrução ou Fundamental incompleto; Fundamental Completo ou médio Incompleto; Médio Completo ou Superior Incompleto; Superior Completo e Não Determinada. As pessoas são classificadas Sem Instrução quando nunca participaram ou concluíram cursos de alfabetização de jovens e adultos, creches, ou curso de Ensino Fundamental. Os critérios estão disponíveis no site do IBGE:

https://www.ibge.gov.br/apps/snig/v1/notas_metodologicas.html?loc=0. Acesso em 8 dez. 2021. Para a situação específica do estado, ver MARANHÃ̃ (2020).

17 Ver IBGE (2017b).
} 
identificação em constante mudança. Haesbaert (2007 apud BARTH; FRAGOSO; REBS, 2011) ressalta que a consequência da amplificação da interação nas redes é a construção e o surgimento de múltiplos territórios. Straubhaar (2019) afirma que

Os sentidos de identificação da audiência podem aumentar na medida em que as formas de mídia trouxerem novas formas culturais atraentes com as quais se identificam. Essa é uma das maneiras pelas quais as camadas de cultura, produção, fluxo e identificação podem aumentar, chegando às múltiplas camadas (STRAUBHAAR, 2019, p.55).

A possibilidade de reação a publicações gera um ambiente de troca que pode resultar em potenciais notícias ou capas do dia. Ferramentas na palma da mão possibilitam tomadas de decisões mais rápidas, permitindo a publicação de conteúdo instantâneo e inédito para o leitor. Os acontecimentos nas cidades estão suscetíveis de se tornarem pautas para os Stories, contendo informações instantâneas, que quebram com as tradicionais barreiras que as redações físicas estabeleciam. O jornalista consegue ter o controle do processo de produção com o smartphone, e o consumidor pode participar ativamente desse processo. Isso gera um ambiente de fácil identificação.

A ausência de materialidade dos ambientes multiusuários online não impede que os processos de apropriação social que os qualificam como lugares virtuais se desdobrem em sentimentos de posse e pertença, caracterizando a vinculação identitária mais intensa que associamos aos territórios (BARTH; FRAGOSO; REBS, 2011, p. 215).

O jornalismo digital local no Maranhão vem se adaptando às novas realidades. Usando redes sociais, os veículos garantem maior número de acessos aos sites, em um importante sistema de captação de cliques. Quando analisamos o uso de plataformas como o Stories percebemos um projeto iniciante e em formação. "A adesão dos grandes veículos jornalísticos à proposta dos Stories manifesta uma estrutura que ainda está em vias de se estabelecer, onde os padrões jornalísticos ainda não estão totalmente inseridos" (COSTA, 2020, p. 39).

\section{O Maranhão do Instagram Stories}

O levantamento para este artigo nos perfis mencionados foi realizado de 14 de junho a 18 de junho de 2021. Ao todo, foram coletadas 153 postagens publicadas no Instagram Stories de O Imparcial Online, do Imirante e do Imperatriz Online. Esses jornais foram escolhidos devido aos locais de produção (São Luís e Imperatriz) e à alta 
quantidade de seguidores se comparados a outros jornais e portais do país. Separadamente, as contas de Imirante, Imperatriz Online e O Imparcial Online têm (até a realização do levantamento) 467 mil, 201 mil e 195 mil seguidores, respectivamente. Os números são maiores, por exemplo, que as contas do Jornal do Brasil (18,3 mil) ${ }^{18}$ e do G1 Maranhão (55,1 mil) ${ }^{19}$.

Em um primeiro momento, o levantamento seria realizado apenas nos perfis dos jornais da capital. Contudo, isso poderia gerar uma distorção em relação à localização na produção para as redes sociais. Nesse sentido, a escolha do Imperatriz Online foi estratégica, com o objetivo de entender como o Maranhão está sendo representado no continente, podendo gerar uma nova identificação de pertencimento da audiência.

As notícias foram catalogadas manualmente. Após assistir aos Stories, a data, o nome do veículo, a natureza da publicação (fotografias ou vídeos), as editorias e o local onde ocorreu a notícia foram separados em categorias. Além disso, foram observados dados como os links das publicações, os chapéus ${ }^{20}$, as manchetes e os templates, com as logomarcas e cores dos jornais. Em postagens especiais, as produções visuais eram identificadas como vídeo ou imagem e, posteriormente, descritas de forma detalhada.

Vale lembrar que o período da coleta estava inserido no contexto da pandemia de Covid-19. Em junho de 2021, o Brasil atingiu a triste marca de mais de 500 mil mortes pela doença. Até o último dia de catalogação, o Maranhão chegou a 307.814 casos e 8.716 mortes em decorrência do novo coronavírus ${ }^{21}$. Números que forçaram modificações drásticas na rotina de tomada de decisão e produção jornalística no estado.

Durante uma semana, o Imperatriz Online (ITZ Online) teve o maior número de publicações nos Stories (62), seguido de O Imparcial, com 61, e do Imirante, com 30 postagens. A maior parte das publicações foram fotografias, unidas ao chapéu (no caso

\footnotetext{
$18 \mathrm{O}$ perfil no Instagram pode ser acessado no link https://www.instagram.com/jornaldobrasil_oficial/. $19 \mathrm{O}$ perfil no Instagram pode ser acessado no link https://www.instagram.com/g1maranhao/. ${ }^{20}$ Chapéu é o jargão jornalístico que define as palavras usadas acima do título da matéria. Geralmente resumem o assunto.

${ }^{21}$ Dados disponíveis no Boletim Epidemiológico da Secretaria Estadual de Saúde do Maranhão. Disponível em: https://www.saude.ma.gov.br/wp-content/uploads/2021/o6/BOLETIM-19-06.pdf. Ver BOLETIM (2021).
} 
do ITZ Online) e às manchetes ${ }^{22}$ e sutiãs ${ }^{23}$ das notícias (no caso de O Imparcial Online). Barth; Fragoso e Rebs (2011) explicam que as publicações de imagens e texto constroem uma referência ao mundo físico para recriar um território no ambiente virtual.

É importante atentar que apenas um jornal teve o cuidado de usar imagens correspondentes às notícias. Na maior parte das publicações do ITZ Online, as fotografias mostraram a localidade da notícia, enquanto os outros jornais utilizaram bancos de dados que não condizem com a realidade, ou mapas que identificam o local de publicação das notícias do continente.

Um exemplo é o caso de um pastor, policial e professor que foi preso por estuprar um adolescente de 15 anos na cidade de Itaipava do Grajaú, a 451,8 km de São Luís. O caso foi registrado na delegacia de Barra do Corda. Todos os três jornais publicaram a notícia, mas a utilização das imagens para a representação dela foi diferente.

O Imirante usou a imagem de um mapa do Maranhão, com o nome da cidade de ocorrência grafado em branco e um ponto da mesma cor indicando a localização. $\mathrm{O}$ Imparcial Online optou por utilizar a fotografia de uma pessoa vestida com uma camisa preta com as palavras Polícia Civil, fechando uma viatura. O veículo tinha linhas de cores verdes. Aparentemente, a viatura não é do Maranhão, já que os veículos usados pela polícia são brancos com as cores preto, azul e vermelho. Acima, um emoji de uma sirene azul. Por último, o ITZ Online fez a publicação da imagem da entrada da delegacia de polícia de Barra do Corda. No primeiro plano, havia uma viatura da polícia. A falta de uma imagem característica do lugar pode levar os habitantes daquela cidade a não se reconhecerem na representação daquele espaço.

Quando a economia se torna dominada por monopólios de produção, duplicados por monopólios de distribuição (monopsônios), a presença de preços administrados é um handicap não só para todo o corpo social, como, principalmente, para os habitantes das localidades isoladas, as coletividades rurais vizinhas e os camponeses isolados (SANTOS, 2007, p. 115).

\footnotetext{
${ }^{22}$ As manchetes são os títulos das matérias. Geralmente, são escritas em letras garrafais, dando destaque ao assunto.

${ }^{23} \mathrm{O}$ sutiã é uma pequena composição textual localizada abaixo da manchete. O objetivo é dar destaque às principais informações do texto.
} 
Barth; Fragoso e Rebs (2011) pontuam que as pessoas são ligadas no espaço virtual por meio das interações imagéticas e textuais. Nesse sentido, ao publicar uma foto de todo o mapa do Maranhão, o Imirante acaba ampliando uma notícia de cunho local, perdendo ou apagando cenários que deveriam ser pontuados e levados em consideração. Além disso, ao publicar uma foto de uma viatura de outro lugar, o Imparcial revela um descuido com o regionalismo e o pertencimento daquela notícia. Sem poder se reconhecer naquele espaço, a população deixa de criar laços com o ambiente virtual. Imagens, textos, expressões são importantes para pavimentar o território para uma população.

É necessário pontuar que essa identificação com o espaço pode ocorrer pela forma como essas notícias são anunciadas: pelo uso de regionalismos, de emojis, de interações ou, até mesmo, pela localização dessas notícias. "[As redes sociais] possibilitam a interação e consumo de conteúdos criados por outros interagentes, cujas conexões são públicas” (ASSIS, 2020, p. 221). Com isso, sem publicar imagens do local da ocorrência, os veículos reduzem a possibilidade de interação com o conteúdo, o que aumenta as chances de os consumidores rejeitarem as notícias, passando para a próxima publicação.

A construção do território virtual pode ser corroborada pela origem do acontecimento jornalístico. O Imparcial e o Imirante têm a maior parte de publicações de notícias e imagens da Região Metropolitana de São Luís, uma área que abrange todo o litoral oeste e parte do litoral leste. Já o ITZ Online tem notícias oriundas de Imperatriz, Santa Inês, Bacabal e São Luís. 


\section{Figura 1 - Levantamento das cidades por publicação nos três perfis jornalísticos}
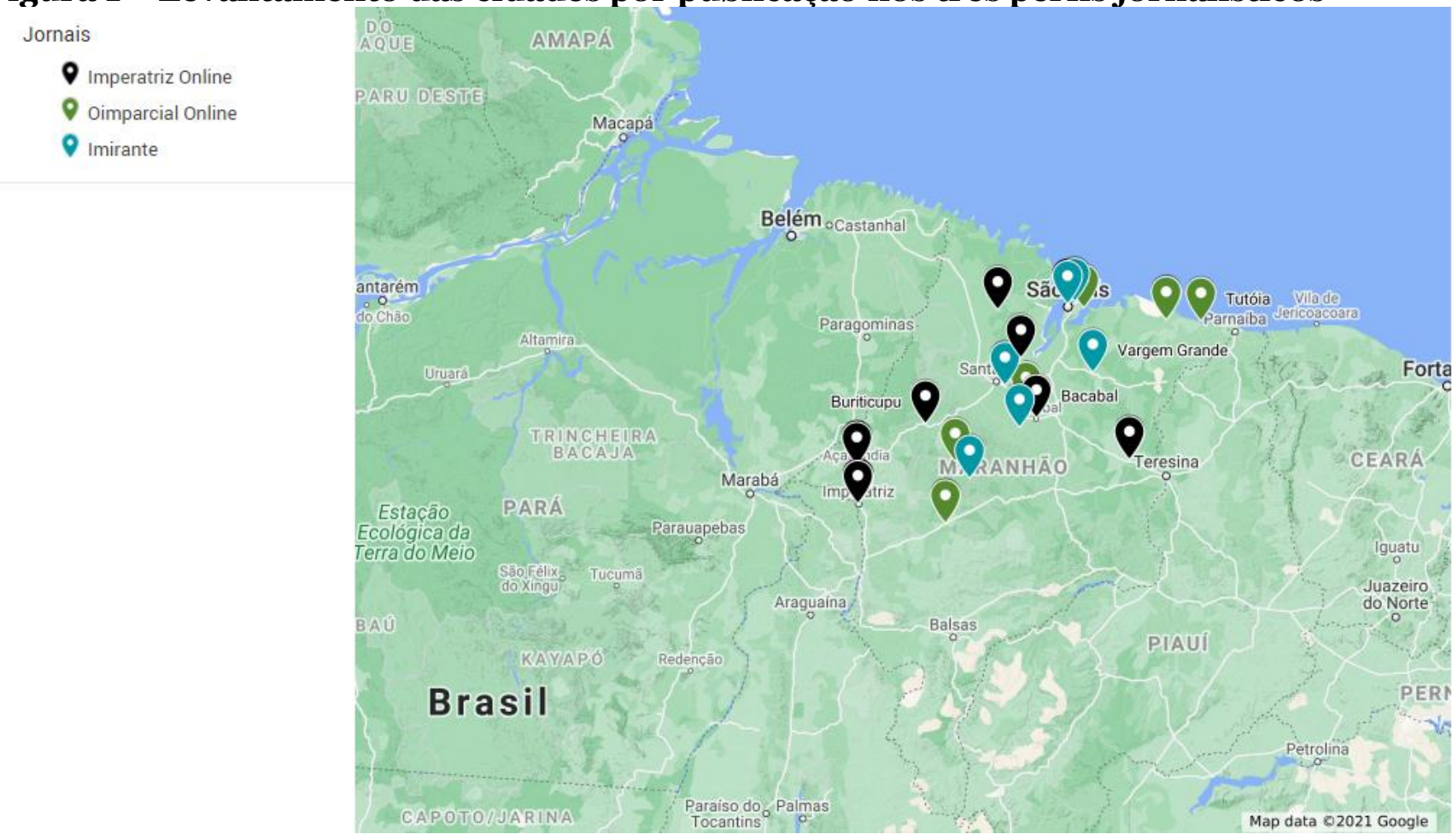

Fonte: Elaboração dos autores a partir do Google Maps

O Imperatriz Online tem uma representação mais diversa das cidades do interior. No mapa produzido durante o levantamento é possível verificar que as notícias são decorrentes de fatos que acontecem em quase todas as macrorregiões do Estado. Importante salientar que a produção jornalística não teve muitos assuntos sobre o sul do Maranhão24, onde está o principal polo produtor de soja do meio norte do país. Notícias sobre economia não apareceram durante o levantamento, mesmo a região sendo importante polo de produção de soja e criação de gado do estado.

Por outro lado, O Imparcial e o Imirante constroem um território virtual do Maranhão por meio de notícias e imagens centradas em São Luís. Ambos representam São Luís em mais de $32 \%$ dos posts, enquanto Imperatriz não aparece ou é representada em poucas postagens. Quando analisamos a produção do ITZ Online é possível identificar um silenciamento de notícias sobre São Luís.

Quando observadas as imagens sobre a pandemia de Covid-19, grande parte do conteúdo publicado nos jornais da capital sobre o interior e a vacinação são

\footnotetext{
24 A região faz parte da nova fronteira agrícola da soja. Formada pelos Estados do Maranhão, Tocantins, Piauí e Bahia, tem uma topografia plana e condições climáticas favoráveis à monocultura do grão. Atualmente, estima-se que a colheita da soja no Matopiba represente aproximadamente $12 \%$ da produção nacional. Ver CRELIER (2021), PAES (2021), LOPES e TOOGE (2021).
} 
provenientes de bancos de imagens gerais, revelando uma ausência da reportagem no local. O perfil do Imperatriz Online publicou o maior número de notícias sobre o interior do Maranhão, possibilitando que Imperatriz tivesse mais informações divulgadas sobre a pandemia, vacinação e boletins. Ao todo, foram 30 notícias catalogadas sobre o assunto nos três perfis pesquisados: $23 \%$ têm como procedência Imperatriz; 16,7\%, São Luís e 30\% falam sobre o Maranhão em geral.

Santos (2007) revela que esse é um movimento comum às comunidades que são periféricas. "A medida que se vai descendo para a periferia (em termos de acessibilidade), as autoridades e as administrações com as quais se é obrigado a transgredir detêm cada vez menos o prodígio e os meios para uma ação eficaz e rápida” (SANTOS, 2007, p.113). Esse movimento se torna claro ao analisarmos a origem dos fatos noticiados nos Stories do Imperatriz Online. A maior parte é gerada em Imperatriz e Açailândia, as duas maiores cidades da região tocantina.

Voltando-se para a ilha, a grande mídia maranhense tende a publicar mais notícias oriundas da capital. São notícias sobre polícia, política, saúde, economia e cultura. Esquecidos no continente, seis milhões de pessoas não encontram notícias suficientes sobre o local onde moram nos grandes perfis noticiosos do Maranhão. Quando analisamos as notícias sobre política, cultura e culinária essa ausência se torna mais clara.

No somatório das publicações dos três jornais, a maior parte é composta por notícias de polícia $(25,5 \%)$, seguidas pelas de saúde $(13,7 \%)$, cidade $(8,5 \%)$, comunidade $(7,2 \%)$, economia $(6,5 \%)$, política $(5,9 \%)$ e cultura $(5,2 \%)$. Posts sobre esportes somaram 3,3\%. A percentagem de notícias sobre emprego e culinária se equivaleram: cada tema teve $1,3 \%$ de representatividade na amostragem. Educação esteve presente em apenas $0,7 \%$ das postagens e concursos, em 0,6\%. As capas do jornal impresso de O Imparcial são rotineiramente postadas e representaram 2,6\% das publicações no período. O Impacial também inclui em sua rotina a publicação de uma "foto ímpar": elas representaram 3,9\% das publicações. Houve poucas publicações com caixas de perguntas (3,3\%), recurso nativo dos Stories, e uma tímida presença de publicações em vídeo (o,7\%). Posts publicitários alcançaram o patamar de 8,5\% dos conteúdos publicados 25 .

\footnotetext{
$25 \mathrm{Na}$ amostragem, 1,3\% das publicações foram categorizadas como "sem classificação" por não se enquadrarem nas categorias definidas pelos autores.
} 
É necessário ressaltar que a editoria de comunidade só existe nos Stories do Imperatriz Online. Mostrando as dificuldades dos bairros de Imperatriz, o perfil denuncia realidades sociais valendo-se de conteúdos audiovisuais enviados pelos leitores. Bradshaw (2014) explica que as redes transformaram a atuação do usuário na produção da notícia. "Os usuários podem agora ultrapassar o jornalista e a história, chegar à testemunha, à cena; ao que está ocorrendo no momento" (BRADSHAW, 2014, p. 116).

Ao publicar vídeos dos próprios leitores, além de alterar as práticas jornalísticas, dando maior espaço para o leitor, os veículos permitem um enlace emocional com o acontecimento. A população consegue ver a própria rua, o hospital do qual depende, que antes não apareciam em outros perfis noticiosos. A oportunidade de atuar como produtor e consumidor dessas notícias garante ao leitor a sensação de pertencimento à comunidade virtual.

Para Costa (2020), a efemeridade nos Stories força o jornalismo a criar uma relação emocional com o consumidor da notícia. $\mathrm{O}$ autor explica que o uso de hashtags, marcação de arrobas, utilização de caixas de perguntas e enquetes permitem uma maior aproximação do público com aquilo que está sendo postado.

Dentre os três perfis analisados, apenas o jornal O Imparcial usou esses recursos. A publicação da "Foto Ímpar" (ver figura 2), a utilização de caixas de perguntas e a possibilidade de repost facilitam a identificação do usuário com a página. Nesse sentido, é perceptível a tentativa de aproximação com o leitor. "O jornalismo que não experimentar novas linguagens e ferramentas, corre, ainda mais, o risco de ser esquecido, de uma postagem para outra" (ASSIS, 2020, p. 221). 
Figura 2 - Exemplos de postagens e repostagens no Instagram de @oimparcial

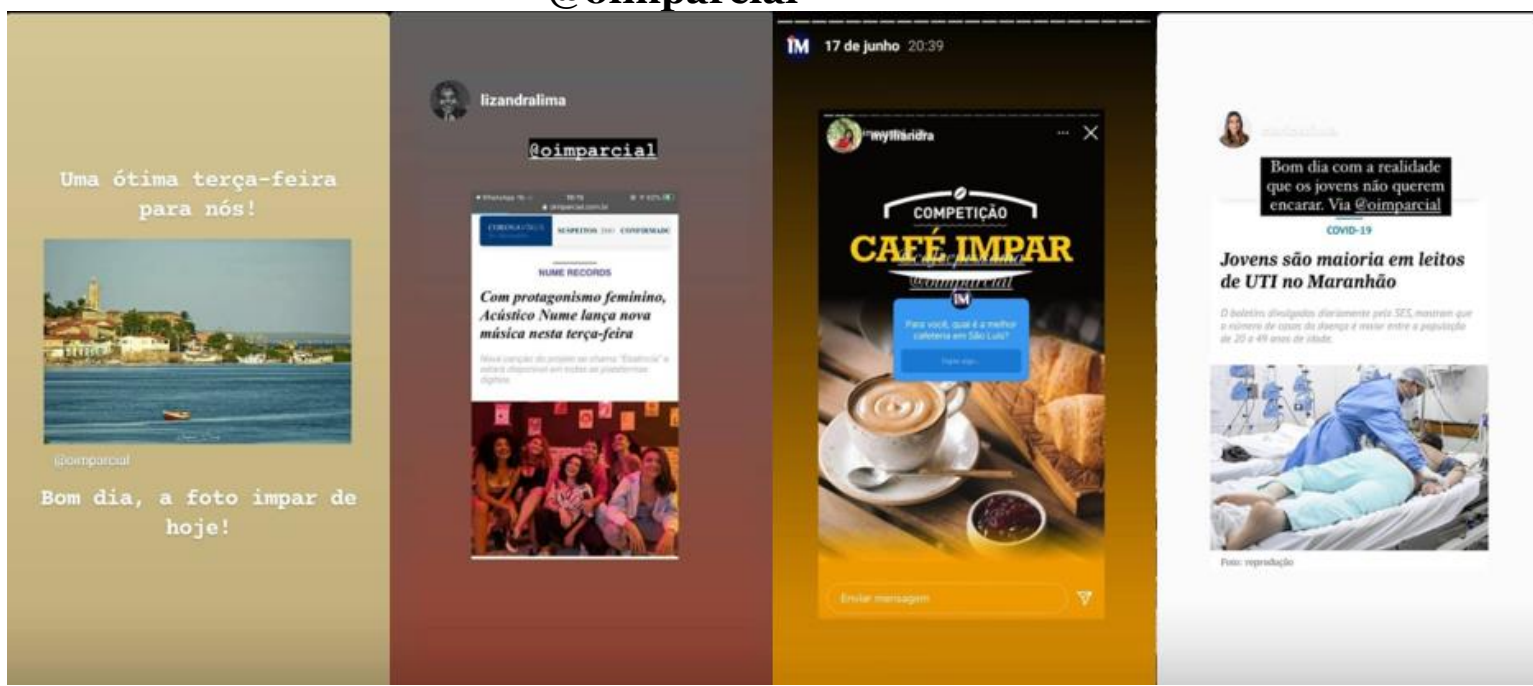

Fonte: @oimparcial

É necessário atentar para a problemática do silenciamento do conteúdo político nos Stories das páginas pesquisadas. O percentual de postagens de notícias sobre a política municipal, estadual ou regional foi de 3,3\% no O Imparcial, 6,7\% no Imirante e $8,1 \%$ no Imperatriz Online. Para Bradshaw (2014), isso pode ser justificado pelos locais de uso das redes sociais.

Esta mudança não se trata apenas de pessoas com acesso à internet, mas sobre os contextos nos quais este acesso é feito. O local de trabalho está se tornando um lugar-chave para o consumo de notícias online (Boczkowski, 2010), levando a um aumento do consumo de conteúdos sociais "seguros" tais como resultados de esportes e jornalismo de celebridades, mas não noutros tipos de temas, como a política (BRADSHAW, 2014, p. 113).

Das quatro notícias divulgadas sobre política nos dois perfis noticiosos da capital, O Imparcial teve o maior número de publicações: três. Duas versavam sobre as decisões do Governo do Maranhão durante a gestão da pandemia, e uma tinha como tema a suspensão das atividades na Câmara Legislativa de São Luís. Por outro lado, o ITZ Online teve praticamente uma notícia publicada por dia sobre o tema, todas voltadas para acontecimentos em Imperatriz.

Durante a semana de observação foram catalogadas dez postagens sobre cultura e culinária. Devido ao fato de a coleta ter acontecido em meio ao período das festividades juninas, esperava-se uma produção maior sobre o tema em todas as 
plataformas. Entretanto, apenas os perfis da capital produziram publicações sobre o tema. Nessas produções, estão vídeos, reposts, fotografias e receitas.

É necessário destacar que tanto O Imparcial quanto o Imirante produziram narrativas sobre o que eles chamam de "São João do Maranhão". Fotos, imagens, músicas remetiam ao Bumba-meu-boi e ao Tambor de Crioula. Patrimônio da Humanidade e do Brasil, essas danças têm prevalência na capital e regiões próximas, como a Baixada Maranhense. No interior, as atividades juninas são compostas por duelos de quadrilhas e brincadeiras. Um estado plural que não foi mostrado na cobertura desses jornais durante o período.

\section{Considerações finais}

O objetivo deste artigo foi analisar o conteúdo noticioso efêmero para os Stories produzido por três veículos maranhenses. Durante 24 horas, os seguidores de tais perfis podem acessar e consumir a produção audiovisual disponível no recurso do Instagram. Muitos conteúdos não passam por uma edição de corte ou redução de tempo, revelando uma falta de cuidado com a orientação e o enquadramento das imagens para o ambiente virtual das redes sociais. Mesmo com modificações impostas pela plataforma, verificou-se que o conteúdo ainda mantém as características jornalísticas apontadas por Otto Groth (2011): a publicidade, a atualidade, a periodicidade e a universalidade.

Gratuitos e de fácil acesso, os Stories garantem maior alcance, novos seguidores e uma maior diversidade de consumidores. Para as empresas, os sites de redes sociais são proveitosos devido ao baixo investimento e ao alto retorno. Os links são importantes direcionadores para os portais de notícias. Aliado a isso, a grande quantidade de seguidores possibilita o uso comercial desses espaços, com a veiculação de peças publicitárias.

O levantamento revela a possibilidade de participação do leitor no conteúdo publicado. Gravar, atuar, interagir na produção de notícias facilita a construção de emoções entre os perfis noticiosos e os seguidores. Com isso, é possível que as contas ganhem um número cada vez maior de consumidores nos próximos anos.

Outro ponto observado durante a coleta de dados é a dificuldade do jornalismo maranhense em representar o Maranhão nos Stories. Concentrados na Ilha de São Luís, os perfis noticiosos pouco mostram o continente em suas produções textuais ou visuais. Passam ao leitor uma unificação cultural, política e econômica em torno da 
capital. Mesmo em pautas importantes não conseguem abordar o continente de uma forma mais diversa.

Essa dificuldade pode estar relacionada à distância das redações em relação ao fato noticioso e o acesso à internet precário em algumas áreas do Maranhão. Por ser um estado de grandes proporções territoriais, torna-se custoso enviar uma equipe para os locais distantes da capital com o objetivo de apurar a notícia. Todo esse movimento é feito através de WhatsApp e redes sociais. Nesse sentido, o uso de fotografias de bancos de imagens generalistas revela um estado pouco explorado pela mídia e uma falta de empenho para a criação de um material próprio para as redes. Tais potenciais não foram aproveitados pelos gestores dos perfis analisados.

Essa baixa publicação sobre o interior permite que o continente continue às margens do noticiário no Instagram Stories. Não é proporcionado a essas localidades o direito de saber ou conhecer os fatos marcantes sobre economia, política ou cultura. Apenas notícias negativas sobre a editoria de polícia promovem uma generalização de assuntos sobre o interior, revelando cidades violentas e perigosas. Assim, o Stories dos jornais da capital ainda são extensões das rotinas produtivas dos portais de notícias, que adotam essa abordagem.

Iniciativas como o ITZ Online podem favorecer uma diversificação de territórios pontuada nos estudos de Barth, Fragoso e Rebs (2011). Com postagens sobre fatos do continente e com amplo alcance, eles garantem que as pessoas de outras localidades tenham conhecimento sobre a cultura, a política, infraestrutura, e a economia de locais apagados pela mídia tradicional. Com imagens dos consumidores e a maior capacidade de interação, permitem que a comunidade sinta o sentimento de pertencimento àquele espaço virtual, mesmo que por $24 \mathrm{~h}$.

A baixa escolaridade e a dificuldade no acesso à internet ainda são grandes empecilhos para iniciativas jornalísticas em sites de redes sociais. No Maranhão, pesquisa do IBGE revelou que a maioria da população tem acesso à internet via mobile e por pacotes de dados de baixa qualidade (CRESCE, 2021). Um problema que pode dificultar a curto prazo a interação entre os leitores e os perfis noticiosos. Essa dificuldade, entretanto, poderá ser superada com novos pacotes que empreguem a tecnologia $5 \mathrm{G}$, em implementação no Brasil.

A pandemia de Covid-19 permitiu um avanço do uso de sites de redes sociais por perfis noticiosos. Em constante atualização, esses territórios virtuais estão se adaptando e se reinventando rapidamente para atender aos novos consumidores que 
chegam diariamente. Após esse período, o jornalismo maranhense deverá atentar para parâmetros importantes nesses territórios virtuais.

Com uma internet mais rápida e veloz, esses perfis terão mais concorrentes profissionais e não profissionais. O espaço poderá ficar saturado de ofertas de perfis noticiosos e blogs. Cabe a esses portais realizarem uma adaptação na linguagem audiovisual para os Stories. Ao tentar se diferenciar, a melhor saída poderia ser a geração de conteúdo nativo para as redes. Reposts dariam lugar a chamadas criativas com linguagens adequadas para chamar a atenção do leitor, realizadas pelos próprios jornalistas.

O cenário pós-pandemia pedirá mais investimentos em sites de redes sociais, que vêm registrando crescimento contínuo. Pequenas produções, de baixo custo, curta duração e rápida edição poderão ser uma tendência adotada por esses portais. Com isso, essas publicações ganhariam mais características jornalísticas no pós-pandemia, mostrando um Maranhão mais diverso e plural. A contribuição dos seguidores também pode ajudar nesse sentido.

\section{Referências}

ANDERSON, C.; BELL, Emily; SHIRKY, Clay. Jornalismo pós-industrial. Revista de Jornalismo ESPM, São Paulo, n. 5, ano 2, abr./jun. de 2013.

ASSIS, Ingrid. Jornalismo Autodestrutivo, no Snapchat e Stories do Instagram, e o consumo de informação na Pós-Modernidade. In: Más sobre Periodismo y Derechos Humanos Emergentes. (pp. 221-234). Sevilla: IdUs, 2020, p. 221-234. Disponível em: <https://idus.us.es/bitstream/handle/11441/97255/Cap\%c3\%adtulo\%2016.pdf?sequ ence $=1 \&$ isAllowed $=\mathrm{y}>$. Acesso em 18 jul. 2021.

BARTH, Daiani; FRAGOSO, Suely. REBS, Rebeca. Territorialidades virtuais: identidade, posse e pertencimento em ambientes multiusuário online. Matrizes, v.5, n.1, 2011, p. 211-

225. <https://www.revistas.usp.br/matrizes/article/view/38317/41166>. Acesso em 18 jul. 2021.

BOLETIM EPIDEMIOLÓGICO COVID-19. Boletim Informativo Diário, São Luís, 19 jun. 2021. Disponível em: <https://www.saude.ma.gov.br/wpcontent/uploads/2021/o6/BOLETIM-19-06.pdf>. Acesso em 18 jul. 2021.

BRADSHAW, Paul. Instantaneidade: Efeito da rede, jornalistas mobile, consumidores ligados e o impacto no consumo, produção e distribuição. In: Canavilhas, João (Org.). 
WEBJORNALISMO: 7 características que marcam a diferença. Covilhã: Livros Labcom,Covilhã, Livros Labcom. 2014. Disponível em: <https://www.labcom.ubi.pt/ficheiros/20141204201404_webjornalismo_jcanavilhas.pdf>. Acesso em 18 jul. 2021.

CASTELLS, Manuel. A sociedade em rede - A era da informação: economia, sociedade e cultura. São Paulo: Paz e Terra, 2006.

COMO criar e o que colocar nos destaques do Instagram. Blog Comercial, 4 jul. 2019. Disponível em <https://business.instagram.com/blog/como-criar-e-o-que-colocarnos-destaques-do-instagram?locale=pt_BR>. Acesso em 8 dez. 2021.

COSTA, Érica Barroso. Narrativas Jornalísticas digitais nas Redes Sociais: periódicos brasileiros e portugueses em formato de stories. 2020. Dissertação (Mestrado em Ciências da Comunicação - Faculdade de Letras, Universidade do Porto, Porto, 2020. Disponível em: <https://repositorioaberto.up.pt/bitstream/10216/130207/2/429957.pdf>. Acesso em 18 jul. 2021.

CRELIER, Cristiane. Estimativa de julho prevê safra recorde de 256,1 milhões de toneladas em 2021. Agência IBGE, Brasília, 10 de ago. de 2021. Disponível em<https://censos.ibge.gov.br/agencia-noticias/2012-agencia-denoticias/noticias/31326-estimativa-de-julho-preve-safra-recorde-de-256-1-milhoesde-toneladas-em-2021>. Acesso em 3 jan. 2022.

CRESCE o número de domicílios com acesso à internet no Maranhão, diz pesquisa do IBGE. Imirante, São Luís, 14 abr. 2021. Disponível em: <https://imirante.com/saoluis/noticias/2021/o4/14/cresce-numero-de-domicilios-com-acesso-a-internet-nomaranhao-diz-pesquisa-do-ibge.shtml>. Acesso em 20 jun. 2021.

DIGITAL 2021: Global Overview Report. We are social, Nova York, 2021. Disponível em <https://wearesocial.com/digital-2021>. Acesso em 18 jul. 2021.

DIGITAL News Report 2021. Reuters Institute, Oxford, 2021. p. 164. Disponível em: <https://reutersinstitute.politics.ox.ac.uk/sites/default/files/2021o6/Digital_News_Report_2021_FINAL.pdf>. Acesso em 18 jul. 2021.

GROTH, Otto. O poder cultural desconhecido. Fundamentos da Ciência dos Jornais. Tradução de Liriam Sponholz. Petrópolis: Vozes, 2011.

IBGE - Instituto Brasileiro de Geografia e Estatística. Cidades. Rio de Janeiro: 2017. Disponível em < https://www.ibge.gov.br/cidades-e-estados/ma/sao-luis.html>. Acesso em 29 dez. 2021.

IBGE - Instituto Brasileiro de Geografia e Estatística. Cidades. Rio de Janeiro: 2017a. Disponível em < https://cidades.ibge.gov.br/brasil/ma/imperatriz/panorama $>$. Acesso em 29 dez. 2021.

IBGE - Instituto Brasileiro de Geografia e Estatística. Cidades. Rio de Janeiro: 2017b. Disponível em < https://cidades.ibge.gov.br/brasil/ma/panorama>. Acesso em 29 dez. 2021. 
IMIRANTE.COM: 20 anos de credibilidade no dia a dia do Maranhense. Imirante, São Luís, 18 set. 2020. Disponível em:<https://imirante.com/maranhao/noticias/2020/o9/18/imirante-com-20-anosde-credibilidade-no-dia-a-dia-do-maranhense.shtml>. Acesso em 29 dez. 2021.

IMPERATRIZ ONLINE. About. Imperatriz Online, 2013. Disponível em: < https://www.facebook.com/ImperatrizOnline/about/?ref=page_internal >. Acesso em 29 dez. 2021.

LOPES, Fernando; TOOGE, Rikardy. Perspectivas positivas para safra de grãos no Matopiba. Valor Econômico, São Paulo, 3 nov. 2021. Disponível em:<https://valor.globo.com/agronegocios/noticia/2021/11/o3/perspectivaspositivas-para-safra-de-graos-no-matopiba.ghtml>. Acesso em 3 jan. 2022.

MARANHÃO é o estado do Brasil com maior percentual de pessoas sem instrução. G1 Maranhão, São Luís, 15 jul. de 2020. Disponível em <https://g1.globo.com/ma/maranhao/noticia/2020/o7/15/maranhao-e-o-estadodo-brasil-com-maior-percentual-de-pessoas-sem-instrucao.ghtml > . Acesso em 19 jun. 2021.

NUNES, J. et. al. Pelas Entrelinhas da Narrativa: O Posicionamento dos Jornais Impressos na Disputa ao Governo do Maranhão. In.: CONGRESSO BRASILEIRO DE CIÊNCIAS DA COMUNICAÇÃO, 42.; INTERCOM JÚNIOR, 2019, Belém. Anais. Belém: Intercom, 2019. Disponível em: <https://portalintercom.org.br/anais/nacional2019/resumos/R14-0737-1.pdf>. Acesso em 19 jun. 2021.

O IMPARCIAL alcança maior audiência da sua história: 8,6 milhões de acessos. $\mathbf{O}$ Imparcial, São Luís, 02 jun. 2020. Disponível em: <https://oimparcial.com.br/noticias/2020/o6/o-imparcial-alcanca-maioraudiencia-da-sua-historia-86-milhoes-de-acessos/>. Acesso em 29 dez. 2021.

PAES, Gustavo. Panorama Setorial - Força do Matopiba. Fundaj, Brasília, 13 de out. de 2021. Disponível em:<https://www.gov.br/fundaj/pt-br/destaques/observafundaj-itens/observa-fundaj/tecnologias-de-convivencias-com-as-secas/panoramasetorial-forca-do-matopiba>. Acesso em 3 jan. 2022.

RECUERO, Raquel. Redes Sociais na internet. Porto Alegre: Sulina, 2009.

REGIÃO metropolitana de São Luís já tem 1,5 milhão de habitantes. Imirante, São Luís, 10 set. 2015. Disponível em: < https://imirante.com/oestadoma/noticias/2015/o9/10/ilha-ja-tem-mais-de-1-5milhao-de-habitantes/>. Acesso em 29 dez. 2021.

SANTOS, Milton. O espaço cidadão. São Paulo: Ed. Universidade de São Paulo, 2007. p.107-120. 
STORIES: Compartilhe seus momentos do dia a dia. Instagram Brasil. São Paulo, s.d.Disponível em: < https://about.instagram.com/pt-br/features/stories >. Acesso em 29 dez. 2021.

STRAUBHAAR, Joseph. Global, híbrida ou múltipla? A nova geografia cultural das identidades. In.: MOREIRA, S. et. al. Geografias da Comunicação no Brasil, 10 anos. São Paulo: Intercom, 2019, p. 26-57.

ZENHA, Luciana. Redes Sociais Online: o que são as redes sociais e como se organizam? Caderno de Educação, Belo Horizonte, v. 1, n. 49, p. 19-42, ano 20, 2017/2018. Disponível em: < https://revista.uemg.br/index.php/cadernodeeducacao/article/view/2809/1541 >. Acesso em 18 jul. 2021. 